\title{
Correction: Li, Z., et al. Study on the Applicability of the Hargreaves Potential Evapotranspiration Estimation Method in CREST-Distributed Hydrological Model (Version 3.0) Applications. Water 2018, 10, 1882
}

\author{
Zhansheng Li ${ }^{1}$, Yuan Yang ${ }^{1}$, Guangyuan Kan ${ }^{1,2, * \mathbb{D}}$ and Yang Hong ${ }^{1,3, *}$ \\ 1 State Key Laboratory of Hydroscience and Engineering, Department of Hydraulic Engineering, Tsinghua \\ University, Beijing 100084, China; lizs1985@tsinghua.edu.cn (Z.L.); yangyuan15@mails.tsinghua.edu.cn (Y.Y.) \\ 2 State Key Laboratory of Simulation and Regulation of Water Cycle in River Basin, Research Center on Flood \\ \& Drought Disaster Reduction of the Ministry of Water Resources, China Institute of Water Resources and \\ Hydropower Research, Beijing 100038, China \\ 3 School of Civil Engineering and Environmental Science, University of Oklahoma, Norman, OK 73019, USA \\ * Correspondence: kanguangyuan@126.com (G.K.); yanghong@ou.edu (Y.H.); Tel.: +86-176-1157-8592 (G.K.)
}

In the published article [1], the authors realized some errors in the affiliation of Yang Hong and thus wish to make the revisions as below:

1. Add the missed Affiliation 3 "School of Civil Engineering and Environmental Science, University of Oklahoma, Norman, OK 73019, USA" for Yang Hong;

2. Correct the email address of Yang Hong into yanghong@ou.edu.

The authors would like to apologize for any inconvenience caused to the readers by the change. The change does not affect the scientific results. The manuscript will be updated, and the original will remain online on the article webpage, with a reference to this correction.

\section{References}

1. Li, Z.; Yang, Y.; Kan, G.; Hong, Y. Study on the Applicability of the Hargreaves Potential Evapotranspiration Estimation Method in CREST Distributed Hydrological Model (Version 3.0) Applications. Water 2018, 10, 1882. [CrossRef]

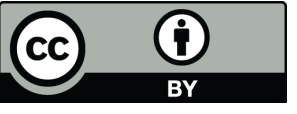

(C) 2019 by the authors. Licensee MDPI, Basel, Switzerland. This article is an open access article distributed under the terms and conditions of the Creative Commons Attribution (CC BY) license (http://creativecommons.org/licenses/by/4.0/). 